\title{
Severe diffuse alveolar hemorrhage related to autoimmune disease: a multicenter study
}

Adrien Mirouse ${ }^{1,2,3,4} \mathbb{D}$, Antoine Parrot ${ }^{5}$, Vincent Audigier ${ }^{6}$, Alexandre Demoule ${ }^{7}$, Julien Mayaux ${ }^{7}$, Guillaume Géri $^{8}$, Eric Mariotte ${ }^{9}$, Nicolas Bréchot ${ }^{10}$, Nicolas de Prost ${ }^{11}$, Mathieu Vautier ${ }^{12}$, Mathilde Neuville ${ }^{13}$, Naïke Bigé ${ }^{14}$, Etienne de Montmollin ${ }^{15}$, Patrice Cacoub ${ }^{1,2,3,4}$, Matthieu Resche-Rigon ${ }^{6}$, Jacques Cadranel ${ }^{5}$ and David Saadoun ${ }^{1,2,3,4^{*}}$

\begin{abstract}
Background: Diffuse alveolar hemorrhage (DAH) occurs during the course of autoimmune disease and may be life threatening. The objective was to assess characteristics and prognosis factors of DAH who required intensive care unit (ICU) admission in patients with autoimmune diseases.

Methods: French multicenter retrospective study including patients presenting DAH related to autoimmune diseases requiring ICU admission from 2000 to 2016.

Results: One hundred four patients (54\% of men) with median age of 56 [32-68] years were included with 79 (76\%) systemic vasculitis and 25 (24\%) connective tissue disorders. All patients received steroids, and 72 (69\%), 12 (11.5\%), and 57 (55\%) patients had cyclophosphamide, rituximab, and plasma exchanges, respectively. During ICU stay, 52 (50\%), 36 (35\%), and 55 (53\%) patients required mechanical ventilation, vasopressor use, and renal replacement therapy, respectively. Factors associated with mechanical ventilation weaning were age $(\mathrm{HR}[95 \% \mathrm{Cl}]$ 0.97 [0.96-0.99] per 10 years, $p<0.0001)$, vasculitis-related DAH (0.52 [0.27-0.98], $p=0.04)$, and time from dyspnea onset to ICU admission (0.99 [0.99-1] per day, $p=0.03$ ). ICU mortality was $15 \%$. Factors associated with alive status at ICU discharge were chronic cardiac failure (HR [95\% $\mathrm{Cl} 0.37$ [0.15-0.94], $p=0.04)$, antiphospholipid syndromerelated DAH (3.17 [1.89-5.32], $p<0.0001)$, SAPS II (0.98 [0.97-0.99], $p=0.007)$, and oxygen flow at ICU admission (0.95 [0.91-0.99] per liter/min, $p=0.04$ ).
\end{abstract}

Conclusion: DAH in autoimmune diseases is a life-threatening complication which requires mechanical ventilation in half of the cases admitted to ICU.

Keywords: Diffuse alveolar hemorrhage, ICU, mechanical ventilation, Plasma exchange, ANCA-associated vasculitis, Anti-MBG-associated vasculitis, IgA-associated vasculitis, Cryoglobulinemia, Systemic lupus erythematosus, Antiphospholipid syndrome

\footnotetext{
* Correspondence: david.saadoun@aphp.fr

'Département Hospitalo-Universitaire

Inflammation-Immunopathologie-Biotherapie (DHU i2B), UPMC Université

Paris 06, UMR 7211, Sorbonne Universités, 75005 Paris, France

2INSERM, UMR_S 959, 75013 Paris, France

Full list of author information is available at the end of the article
}

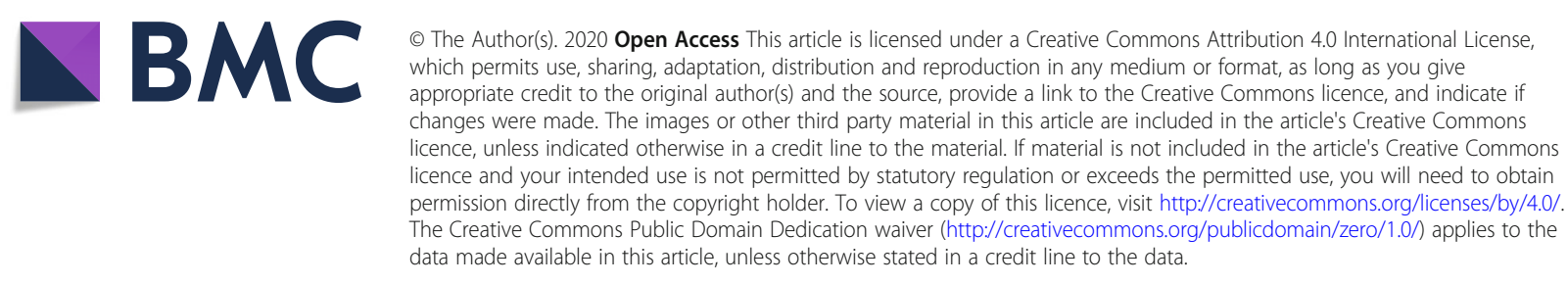




\section{Background}

Diffuse alveolar hemorrhage (DAH) is a form of pulmonary hemorrhage that originates from the pulmonary microcirculation [1]. DAH is usually classified as immune or non-immune [2]. Immune causes represent 30 to $40 \%$ of all DAH cases [3]. Autoimmune diseases associated with DAH include mainly small-vessel vasculitis, systemic lupus erythematosus (SLE), and antiphospholipid syndrome (APS). Immune DAH severity is variable. It can range from asymptomatic forms, diagnosed on systematic chest radiography, to life-threatening complications. Severe forms may lead to acute respiratory failure and require intensive care unit (ICU) management [4]. DAH represents $12 \%$ of ICU admissions in patients with an autoimmune disease [5].

Early recognition and diagnosis are mandatory to initiate adequate treatments. Treatment is based on highdose steroids in combination with cyclophosphamide or rituximab [6-8]. However, in this indication, these treatment regimens are based on case reports and small cohorts with immune DAH of heterogeneous severity. Plasma exchange therapy (PLEX) has been reported as efficient in several case series $[9,10]$. PLEX has been reported as efficient in ANCA-associated vasculitis concerning 1-year renal outcome [11, 12]. These results were not confirmed in a recent phase III study in which plasma exchanges were not associated with end-stage renal disease rate reduction in ANCA-associated vasculitis [13].

Data regarding prognosis and outcome of severe DAH in autoimmune diseases are lacking as these patients are often excluded from large clinical trials [14-16]. In this French multicenter study, we aimed to assess the outcome and prognosis factors of severe DAH in autoimmune diseases and to compare vasculitis- and connective tissue disorder-related DAH.

\section{Methods \\ Design}

We conducted a retrospective French multicenter study in $11 \mathrm{ICU}$. This study was approved by the local ethics committee. All adult patients ( $\geq 18$ years old) with a severe DAH related to an autoimmune disease admitted in the participating ICUs between January 1, 2000, and January 1, 2017, were included. Patients were identified with the International Disease Classification 10 code for auto-immune diseases (lupus, vasculitis, inflammatory myopathy, systemic sclerosis, overlap autoimmune diseases, rheumatoid arthritis) and DAH. DAH was defined as (1) hemoptysis and/or macroscopically hemorrhagic broncho-alveolar lavage, (2) new pulmonary infiltrates, and (3) anemia. DAH was defined as severe if DAH management required ICU admission. Autoimmune diseases included were small-vessel vasculitis and connective tissue disorders. Autoimmune diseases were diagnosed according to international diagnosis criteria [17-19]. Patients were excluded if DAH at admission was related to a non-immune condition such as heart failure or infection. Patients were identified from the ICU databases using codes for acute respiratory failure and for autoimmune diseases. All patients' medical records were reviewed by 2 investigators (AM and DS).

\section{Data collection}

Demographic data, comorbidities, treatments, medical history, and clinical, biological, and radiological findings were abstracted from medical charts. Comorbidities were assessed with the Charlson comorbidity index [20]. Autoimmune diseases manifestations at ICU admission were collected including skin, neurological, joint, gut, and kidney manifestations. Physiological variables, laboratory data, and radiographic findings (chest X-ray and computed tomography [CT] when available) at ICU admission were also reported. Disease severity was assessed using the Simplified Acute Physiology Score (SAPS II) [21]. Patients were classified as having acute respiratory failure if they met the following criteria: severe dyspnea at rest, respiratory rate greater than 30 breaths per minute or clinical signs of respiratory distress, and oxygen saturation less than $92 \%$ or $\mathrm{PaO} 2$ less than $60 \mathrm{mmHg}$ on room air [22]. Hypoxemia severity was assessed using the $\mathrm{PaO}_{2} / \mathrm{FiO}_{2}$ ratio. Fiberoptic bronchoscopy, bronchoalveolar lavage, and the use of lifesustaining treatments (i.e., noninvasive or invasive mechanical ventilation, renal replacement therapy, and vasopressors) were recorded. Diagnosis of the autoimmune disease was made according to the clinical, biological, immunological, and histological findings. Acute respiratory distress syndrome (ARDS) was defined according to the Berlin definition [23]. Acute kidney injury was defined according to the Kidney Disease Improving Global Outcomes definitions [24]. Therapeutic regimens were reported including red blood cell transfusions, standard dose steroids, high-dose steroid pulses, other immunosuppressive therapies, and plasma exchange therapy. ICU-acquired infections were recorded. The diagnosis of infection was confirmed if patients met both following criteria: microbiological identification of a pathogen and administration of related antibiotic treatment.

Mechanical ventilation weaning was defined as extubation without reintubation during the following $48 \mathrm{~h}$. ICU and hospital length of stays and vital status at ICU and hospital discharge were obtained for all patients.

\section{Statistics}

Patients' characteristics were described using medians and interquartile ranges for quantitative variables and counts and percentages for qualitative variables. 
Characteristics of patients requiring mechanical ventilation during their ICU stay were compared to those of patients without mechanical ventilation using either the Wilcoxon rank sum test or Fishers' exact test. Comparisons between patients having received plasma exchanges and not, between those being deceased and being discharged alive, and between those having developed a vasculitis and a connective tissue disorder were performed in the same way. To assess variables associated with the weaning of mechanical ventilation, clinical relevant baseline characteristics significantly associated with the weaning from mechanical ventilation, as well as treatments provided during ICU stay, were included in a multivariate Cox model, where treatment variables are time-varying covariates and death in ICU is considered as a competing event of discharge alive from ICU. The same procedure was used for assessing variables associated with ICU discharge.

\section{Results}

\section{Clinical characteristics of DAH}

During the study period, we identified 104 patients (54\% of men) admitted to the ICU for severe DAH associated with autoimmune disease (Table 1 and supplementary eTable 1). The median age was 56 [32-68] years old. DAH was associated with an autoimmune disease relapse in 28 (27\%) patients. DAH was the first autoimmune disease manifestation in 35 (34\%) patients. A pneumo-renal syndrome was present in 83 (81\%) patients. The median time from onset of respiratory symptoms to ICU admission was 5 [1-21] days. On admission, patients were severely hypoxemic with a $\mathrm{PaO}_{2} / \mathrm{FiO}_{2}$ ratio of 150 [87-229] mmHg. Hemoptysis was present in $53(51 \%)$ patients, and acute respiratory failure was reported in 78 (75\%) patients. Lactate dehydrogenase (LDH) elevation was present in $65(63 \%)$ patients. Bronchoscopy was performed in 83 (80\%) patients and demonstrated macroscopic pulmonary hemorrhage in all cases.

\section{Comparison between patients with connective tissue disorder and vasculitis}

A diagnosis of autoimmune disease was made 5 [2-11] days after hospital admission and 0 [ -1 to 2] days after ICU admission. A small-vessel vasculitis was diagnosed in $79(76 \%)$ patients, and a connective tissue disorder in 25 (24\%). Organ involvement of the autoimmune disease was histologically confirmed in 49 (47\%) cases. Comparison between patients with connective tissue disorder and vasculitis is shown in Table 1 . Patients with vasculitis were older (61 [39-71] vs. $42[27-55]$ years old, $p=$ $0.003)$ and were more often males $(61 \%$ vs. $29 \%, p=$ $0.01)$. Pneumo-renal syndrome was more frequent in patients with a vasculitis diagnosis $(89 \%$ vs. $56 \%, p=$
0.0009). Dyspnea evolution was more acute in patients with a connective tissue disorder (time from dyspnea onset to ICU admission 1 [0-10] day vs. $6[1-24]$ days, $p=$ 0.018). Patients with a connective tissue disorder had lower platelet counts and higher LDH levels on ICU admission.

All patients but one received a specific treatment based on steroids, and 93 (89\%) patients received adjunctive steroid pulse therapy. An immunosuppressive therapy based on cyclophosphamide or rituximab was initiated in $72(69 \%)$ and $12(11.5 \%)$ patients, respectively. Cyclophosphamide and rituximab were associated in $6(6 \%)$ patients. PLEX was initiated in $57(55 \%)$ patients. Patients who received PLEX tended to be more severe at ICU admission (SAPS II: 37.5 [28-49.5] vs. 32.5 [22-41.75], $p=0.073$ ). In univariate analysis, there was no difference in mortality between patients treated or not with PLEX (supplementary eTable-2).

\section{Invasive mechanical ventilation requirement, weaning, and ICU management}

Noninvasive mechanical ventilation was implemented in $33(32 \%)$ patients, failing in $18(55 \%)$ who were subsequently intubated. Invasive mechanical ventilation was required in $52(50 \%)$ patients overall, of whom all fulfilled the ARDS criteria. Patients were intubated 0 [0-2] days after ICU admission. Univariate analysis of factors associated with mechanical ventilation requirement is displayed in Table 2. Duration of mechanical ventilation was 12 [6-22] days. Univariate analysis of factors associated with mechanical ventilation weaning is shown in supplementary e-Table 3. In multivariate analysis, factors associated with a longer mechanical ventilation weaning were age (HR [95\%CI] 0.97 [0.96-0.99] per 10 years, $p<$ $0.0001)$, vasculitis (0.52 [0.27-0.98], 0.04), and time from dyspnea onset to ICU admission (0.99 [0.99-1] per day, $p=0.03$ ) (Fig. 1). The median ICU length of stay was 11 [7-18.8] days.

\section{Factors associated with ICU survival}

Sixteen (15\%) patients died in ICU. Death was attributed directly to refractory autoimmune disease in $5(31 \%)$ cases, to refractory ARDS in $4(25 \%)$ cases, to multiorgan failure in $4(25 \%)$ cases, and to septic shock in 3 (19\%) cases. In univariate analysis, factors associated with ICU mortality are displayed in Table 3 and supplementary e-Table 4 . In multivariate analysis, factors associated with alive status at ICU discharge were chronic heart failure (HR [95\%CI] 0.37 [0.15-0.94], $p=0.037$ ), APS-related DAH (3.17 [1.89-5.32], $p<0.0001)$, SAPS II (0.98 [0.97-0.99], $p=0.007)$, and oxygen flow at ICU admission (0.95 [0.91-0.998], $p=0.04$ ) (Fig. 2).

After ICU discharge, 48 (55\%) patients were followed up with a median duration of 19 [8-38] months. At the 
Table 1 Characteristics of 104 patients with DAH and according to the presence of a vasculitis or a connective tissue disorder

\begin{tabular}{|c|c|c|c|c|}
\hline & All patients $(\boldsymbol{n}=104)$ & Connective tissue disorder $(\boldsymbol{n}=25)$ & Vasculitis $(\boldsymbol{n}=79)$ & $p$ \\
\hline \multicolumn{5}{|l|}{ A. Baseline characteristics } \\
\hline \multicolumn{5}{|l|}{ Demographics } \\
\hline Age, years, median [IQR] & $56[32-68]$ & $42[27-55]$ & $61[39-71]$ & 0.003 \\
\hline Male gender, $n(\%)$ & $56(54 \%)$ & $7(29 \%)$ & $48(61 \%)$ & 0.02 \\
\hline \multicolumn{5}{|l|}{ Comorbidities } \\
\hline Charlson score, median [IQR] & $3[1-4]$ & $2[1-3.5]$ & $3[1-4]$ & 0.23 \\
\hline Previous steroid treatment, $n(\%)$ & $26(25 \%)$ & $10(40 \%)$ & $16(20 \%)$ & 0.064 \\
\hline \multicolumn{5}{|l|}{ Systemic disease, $n$ (\%) } \\
\hline Connective tissue disorder & $25(24 \%)$ & NA & NA & \\
\hline Systemic lupus erythematosus & $12(48 \%)$ & & & \\
\hline Primary antiphospholipid syndrome & $9(36 \%)$ & & & \\
\hline Others* & $4(16 \%)$ & & & \\
\hline Vasculitis & $79(76 \%)$ & NA & NA & \\
\hline ANCA-associated vasculitis & $57(72 \%)$ & & & \\
\hline Anti-GBM disease & $12(15 \%)$ & & & \\
\hline Cryoglobulin-associated vasculitis & $4(5 \%)$ & & & \\
\hline IgA-associated vasculitis & $6(8 \%)$ & & & \\
\hline Inaugural & $76(73 \%)$ & $13(52 \%)$ & $63(80 \%)$ & 0.01 \\
\hline Relapse & $28(27 \%)$ & $12(48 \%)$ & $16(20 \%)$ & \\
\hline \multicolumn{5}{|l|}{ Systemic disease manifestations, n (\%) } \\
\hline DAH & $104(100 \%)$ & $25(100 \%)$ & $79(100 \%)$ & 1 \\
\hline Hemoptysis & $53(51 \%)$ & $10(40 \%)$ & $43(54 \%)$ & 0.25 \\
\hline Cough & $68(65 \%)$ & $17(68 \%)$ & $51(65 \%)$ & 0.81 \\
\hline Acute respiratory failure & $78(75 \%)$ & $20(80 \%)$ & $58(73 \%)$ & 0.6 \\
\hline Renal & $83(81 \%)$ & $14(56 \%)$ & $69(89 \%)$ & 0.0009 \\
\hline Digestive & $7(7 \%)$ & $2(8 \%)$ & $5(6 \%)$ & 0.68 \\
\hline Nervous system & $16(16 \%)$ & $6(24 \%)$ & $10(13 \%)$ & 0.21 \\
\hline Joint & $20(19 \%)$ & $4(16 \%)$ & $16(21 \%)$ & 0.78 \\
\hline Skin & $23(22 \%)$ & $7(28 \%)$ & $16(21 \%)$ & 0.42 \\
\hline \multicolumn{5}{|l|}{ ICU admission characteristics, median [IQR] } \\
\hline SAPS ॥ & $36[25.75-47]$ & $33[26-42]$ & $38[26-48]$ & 0.51 \\
\hline Temperature & $37.9[37-38.6]$ & $38.2[37.2-39.1]$ & $37.7[37-38.5]$ & 0.15 \\
\hline Oxygen flow, L/min & $15[5-15]$ & $12[5-15]$ & $15[5-15]$ & 0.92 \\
\hline $\mathrm{PaO} 2 / \mathrm{FiO} 2$ ratio & $150[87-229]$ & $120[90-230]$ & $157[86-225]$ & 0.64 \\
\hline Time (days) from dyspnea onset to ICU admission & $5[1-21]$ & $1[0-10]$ & $6[1-24]$ & 0.018 \\
\hline Time (days) from first symptoms to ICU admission & $30[11.8-79]$ & $17[10-46]$ & $32[15-88]$ & 0.079 \\
\hline Time (days) from hospital admission to ICU admission & $5[1-12]$ & $7[3-15]$ & $3[0-12]$ & 0.13 \\
\hline \multicolumn{5}{|l|}{ Biological findings at ICU admission, median [IQR] } \\
\hline Hemoglobin, g/L & 86 [72-95] & $87[75-97]$ & 86 [72-95] & 0.73 \\
\hline Leukocytes, G/L & $11.7[8.9-15.6]$ & $11.1[6.4-17.1]$ & $11.7[9.2-15.4]$ & 0.47 \\
\hline Platelets count, G/L & $257[141-353]$ & 102 [53-236] & $278[186-401]$ & $<0.0001$ \\
\hline Creatinine, $\mu \mathrm{mol} / \mathrm{L}$ & 235 [92-433] & $103[71-174]$ & $303[128-520]$ & 0.0002 \\
\hline Urine protein/creatinine, $\mathrm{g} / \mathrm{mmol}$ & $0.19[0.1-0.33]$ & $0.12[0.07-0.25]$ & $0.2[0.1-0.34]$ & 0.17 \\
\hline $\mathrm{LDH}, \mathrm{mmol} / \mathrm{L}$ & 488 [354-905] & 873 [532-1152] & $454[329-714]$ & 0.008 \\
\hline
\end{tabular}

\section{B. ICU management.}


Table 1 Characteristics of 104 patients with DAH and according to the presence of a vasculitis or a connective tissue disorder (Continued)

\begin{tabular}{|c|c|c|c|c|}
\hline & All patients $(\boldsymbol{n}=104)$ & Connective tissue disorder $(\boldsymbol{n}=25)$ & Vasculitis $(\boldsymbol{n}=79)$ & $p$ \\
\hline \multicolumn{5}{|l|}{ ICU management, $n(\%)$} \\
\hline Vasopressor use & $36(35 \%)$ & $8(32 \%)$ & $28(35 \%)$ & 0.81 \\
\hline Renal replacement therapy & $55(53 \%)$ & $6(24 \%)$ & $49(62 \%)$ & 0.001 \\
\hline \multicolumn{5}{|l|}{ Respiratory management } \\
\hline Non-invasive ventilation & $33(32 \%)$ & $8(32 \%)$ & $25(32 \%)$ & 1 \\
\hline Mechanical ventilation & $52(50 \%)$ & $11(44 \%)$ & $41(52 \%)$ & 0.65 \\
\hline ARDS diagnosis & $52(50 \%)$ & $13(52 \%)$ & $43(55 \%)$ & 0.82 \\
\hline Prone positioning & $11(21 \%)$ & $3(12 \%)$ & $8(11 \%)$ & 1 \\
\hline Mechanical ventilation duration, days, median [IQR] & $12[6-22]$ & $4[4-18]$ & 13 [9-33] & 0.007 \\
\hline Red blood cell transfusion & $78(75 \%)$ & $16(64 \%)$ & $62(80 \%)$ & 0.33 \\
\hline \multicolumn{5}{|l|}{ Systemic disease management, $n$ (\%) } \\
\hline Time (days) from first symptoms to diagnosis & $31[11.5-77]$ & 19.5 [10-53] & $32[15-86]$ & 0.14 \\
\hline Steroids & $103(99 \%)$ & $25(100 \%)$ & $78(99 \%)$ & 1 \\
\hline Steroids pulse therapy & $93(89 \%)$ & $20(80 \%)$ & $73(92 \%)$ & 0.13 \\
\hline Cyclophosphamide & $72(69 \%)$ & $9(36 \%)$ & $63(80 \%)$ & $<0.0001$ \\
\hline Rituximab & $12(11.5 \%)$ & $1(4 \%)$ & $11(14 \%)$ & 0.29 \\
\hline PLEX & $57(55 \%)$ & $6(24 \%)$ & $51(65 \%)$ & 0.0009 \\
\hline Number of PLEX & 7 [4.3-9.5] & $4[2-9]$ & $7[5-9]$ & 0.32 \\
\hline Bacterial superinfection, $n$ (\%) & $30(29 \%)$ & $3(12 \%)$ & $27(34 \%)$ & 0.042 \\
\hline Hospital mortality, $n$ (\%) & $16(15 \%)$ & $3(12 \%)$ & $13(17 \%)$ & 0.76 \\
\hline Follow-up & $48(55 \%)$ & $13(59 \%)$ & $35(53 \%)$ & 0.65 \\
\hline Length of follow-up (months) & 19 [8-38] & 37 [11-66] & $15[7-28]$ & 0.003 \\
\hline Chronic renal failure** & $22(65 \%)$ & $4(80 \%)$ & $18(62 \%)$ & 0.33 \\
\hline Dialysis** & $8(24 \%)$ & $1(20 \%)$ & $7(24 \%)$ & 0.42 \\
\hline
\end{tabular}

*Other connective tissue disorders: mixed connective tissue disorder ( 3 patients) and myositis (1 patient)

**Percentage based on the number of followed up patients at risk (patients with pneumo-renal syndrome at admission and with follow-up available)

Abbreviations: ANCA anti-neutrophil cytoplasmic antibody, ARDS acute respiratory distress syndrome, DAH diffuse alveolar hemorrhage, GC glucocorticoid, ICU intensive care unit, LDH lactate dehydrogenase, NA not applicable, PLEX plasma exchange, SAPS Simplified Acute Physiology Score

Table 2 Univariate analysis of factors associated with mechanical ventilation requirement

\begin{tabular}{|c|c|c|c|}
\hline Parameters & $\begin{array}{l}\text { No invasive ventilation } \\
\boldsymbol{n}=52\end{array}$ & $\begin{array}{l}\text { Invasive ventilation } \\
\boldsymbol{n}=52\end{array}$ & $\boldsymbol{p}$ value \\
\hline Age, years, median [IQR] & 50 [29-62] & 58 [39-70] & 0.12 \\
\hline Charlson comorbidity index, median [IQR] & $3[1.3-4.8]$ & $3[1-4]$ & 0.59 \\
\hline Vasculitis, yes, $n(\%)$ & $38(73 \%)$ & $41(79 \%)$ & 0.65 \\
\hline Hemoptysis, yes, $n$ (\%) & $30(58 \%)$ & $23(44 \%)$ & 0.24 \\
\hline Acute respiratory failure, $n(\%)$ & $28(54 \%)$ & $50(96 \%)$ & $<0.0001$ \\
\hline Renal involvement, yes, $n$ (\%) & $40(77 \%)$ & $43(84 \%)$ & 0.46 \\
\hline SAPS II, median [IQR] & 29 [19-37] & $44[33-56]$ & $<0.0001$ \\
\hline $\mathrm{PaO} 2 / \mathrm{FiO} 2$ ratio, median $[\mathrm{IQR}]$ & 205 [123-263] & 108 [75-190] & 0.0003 \\
\hline Time (days) from dyspnea to ICU admission, days, median [IQR] & $6[1-23]$ & $5[1-16]$ & 0.70 \\
\hline Hemoglobin at day 1 , median [IQR] & $8.3[7.4-9.5]$ & $8.6[7.2-9.5]$ & 0.85 \\
\hline Neutrophil count at day 1 , median [IQR] & $8.2[6.4-10.2]$ & $10.6[7.6-18.0]$ & 0.05 \\
\hline LDH at day 1 , UI/L, median[IQR] & $432[317-626]$ & 679 [409-1213] & 0.010 \\
\hline
\end{tabular}

Abbreviations: $\mathrm{Cl}$ confidence interval, $H R$ hazard ratio, ICU intensive care unit, SHR subdistribution hazard ratio 


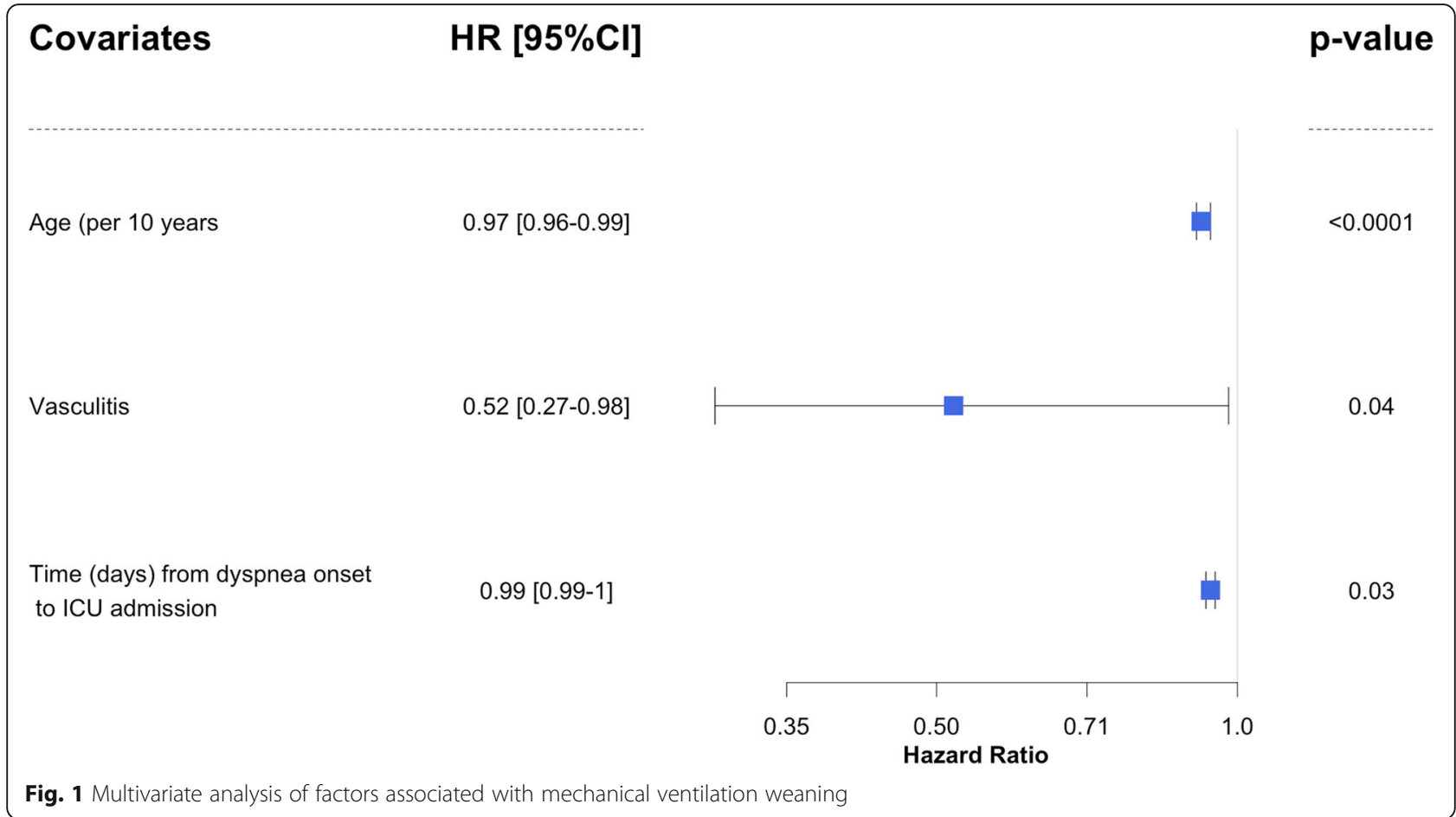

end of follow-up, 22 (65\%) of these patients had a chronic kidney disease and 8 (24\%) still required renal replacement therapy. Twenty-two (47\%) patients had a lung CT-scan evaluation during follow-up showing lung fibrosis for $8(36 \%)$ patients. Pulmonary function testing was performed in 15 (32\%) patients and showed a restrictive pulmonary disorder in $6(40 \%)$ cases.

\section{Discussion}

In this multicenter nationwide French study, we report the largest study assessing the outcome and prognosis factors associated with severe DAH related to autoimmune diseases. The conclusions drawn by this study are that (1) ICU mortality was $16 \%$ reaching $31 \%$ in patients requiring mechanical ventilation; (2) mechanical ventilation was required in half of the cases, of whom all met ARDS criteria; and (3) systemic vasculitis was associated with longer mechanical ventilation duration.

Other studies have reported management and outcomes of patients with DAH, but they have described patients with less severe diseases. Cartin-Ceba et al. have reported outcomes of patients with AAV-related DAH [10]. Some of these patients were asymptomatic and were not hospitalized. Other patients in this study required ICU admission, but they were less severe than in our cohort. Another cohort included patients with variable severity, and DAH was not confirmed by bronchoalveolar lavage in all cases [25].

In the present study, overall ICU mortality was $16 \%$ and reached $31 \%$ of patients who required mechanical ventilation. Mortality from DAH has reduced during the past years, and the mortality in our cohort is in line with recent DAH cohorts $[26,27]$. Major advances in the care of critically ill patients could explain these results. Our results point out that severity at ICU admission is directly linked to ICU mortality. Chronic heart failure has already been reported as associated with a poorer prognosis in patients with DAH [3]. DAH related to autoimmune disease is considered to have a better prognosis compared to non-immune causes of DAH $[3,28]$. This may illustrate the benefit of early aggressive immunosuppressive therapies in this context. However, there is no data comparing prognosis of DAH according to autoimmune diseases. In our study, APS diagnosis was associated with a better outcome. Previous studies of APSrelated DAH reported good outcomes when DAH was controlled [9, 29]. Although our study was not designed to address this question, neither immunosuppressants nor PLEX therapy seemed to improve prognosis.

Half of the patients required invasive mechanical ventilation. Comorbidities and type of autoimmune disease were not risk factors for mechanical ventilation. These results are in agreement with previous studies, suggesting that the underlying medical context is no longer significantly associated with the risk for intubation after adjustment on the severity of the acute disease [30-33]. Age and small-vessel vasculitis were associated with a longer duration of mechanical ventilation. Patients with small-vessel vasculitis required more frequently renal replacement therapy which could explain in part a 
Table 3 Univariate analysis of ICU survival associated factors

\begin{tabular}{|c|c|c|}
\hline \multirow[t]{2}{*}{ Parameter } & \multicolumn{2}{|l|}{ Univariate analysis } \\
\hline & SHR 95\%Cl & $\boldsymbol{p}$ value \\
\hline Age (per 10 years) & $0.87(0.79-0.95)$ & 0.0016 \\
\hline Sex & $1.12(0.75-1.7)$ & 0.58 \\
\hline Charlson comorbidity index & $0.88(0.81-0.97)$ & 0.0078 \\
\hline Chronic respiratory failure & $0.73(0.29-1.82)$ & 0.49 \\
\hline Chronic cardiac failure & $0.34(0.16-0.74)$ & 0.0063 \\
\hline Chronic renal failure & $0.59(0.3-1.17)$ & 0.13 \\
\hline Steroid treatment & $0.78(0.44-1.37)$ & 0.38 \\
\hline Connective tissue disorder & $1.35(0.82-2.22)$ & 0.24 \\
\hline Systemic lupus & $1.07(0.48-2.41)$ & 0.86 \\
\hline Antiphospholipid syndrome & $2.26(1.35-3.78)$ & 0.0018 \\
\hline Other systemic disease & $0.87(0.36-2.09)$ & 0.76 \\
\hline Vasculitis & $1.35(0.82-2.22)$ & 0.24 \\
\hline ANCA-associated vasculitis & $0.95(0.62-1.45)$ & 0.8 \\
\hline Goodpasture syndrome & $1.08(0.7-1.66)$ & 0.73 \\
\hline Cryoglobulin-associated vasculitis & $0.17(0.02-1.68)$ & 0.13 \\
\hline IgA-associated vasculitis & $0.49(0.15-1.6)$ & 0.24 \\
\hline Relapse & $1.07(0.63-1.81)$ & 0.81 \\
\hline Hemoptysis & $1.18(0.79-1.77)$ & 0.42 \\
\hline Acute respiratory failure & $0.57(0.37-0.89)$ & 0.014 \\
\hline Renal involvement & $0.73(0.46-1.14)$ & 0.17 \\
\hline Digestive involvement & $1.31(0.45-3.85)$ & 0.62 \\
\hline Nervous system involvement & $1.21(0.78-1.87)$ & 0.39 \\
\hline Joint involvement & $0.8(0.48-1.34)$ & 0.41 \\
\hline Skin involvement & $0.81(0.48-1.36)$ & 0.43 \\
\hline Other systemic disease manifestations & $1.1(0.93-1.3)$ & 0.25 \\
\hline SAPS ॥ & $0.97(0.96-0.99)$ & $<0.0001$ \\
\hline Oxygen flow & $0.95(0.91-0.98)$ & 0.0032 \\
\hline PAO2 over FiO2 ratio (per 10 points) & $1.02(1-1.04)$ & 0.0099 \\
\hline Time (days) from dyspnea onset to ICU admission & $(0.98-1)$ & 0.13 \\
\hline Time (days) from hospital admission to ICU admission & $1.01(0.98-1.04)$ & 0.6 \\
\hline Hemoglobin at ICU admission & $0.97(0.89-1.05)$ & 0.41 \\
\hline Lymphocytes at ICU admission & $2.51(1.6-3.95)$ & $<0.0001$ \\
\hline Neutrophil count at ICU admission & $1.02(0.98-1.06)$ & 0.45 \\
\hline Platelets count at ICU admission (per 10G/L) & $1.01(0.99-1.02)$ & 0.36 \\
\hline Creatinine at ICU admission (per $10 \mu \mathrm{mol} / \mathrm{L}$ ) & $1(0.99-1.01)$ & 0.72 \\
\hline Urine protein/creatinine ratio & $0.97(0.46-2.02)$ & 0.93 \\
\hline LDH at ICU admission (per 100UI/L) & $0.98(0.94-1.02)$ & 0.31 \\
\hline Vasopressor use & $0.29(0.18-0.47)$ & $<0.0001$ \\
\hline
\end{tabular}

Abbreviations: $\mathrm{Cl}$ confidence interval, $H R$ hazard ratio, $I C U$ intensive care unit, SAPS Simplified Acute Physiology Score, SHR cause specific hazard ratio

negative impact on ventilation weaning [34]. Early ICU admission after dyspnea onset was associated with a shorter duration under mechanical ventilation. Dumas et al. already reported that direct ICU admission was associated with better outcomes in a large study of critically ill patients with systemic rheumatic disease [5].

Our study has several limitations. First, given the retrospective design over a long period of time, 


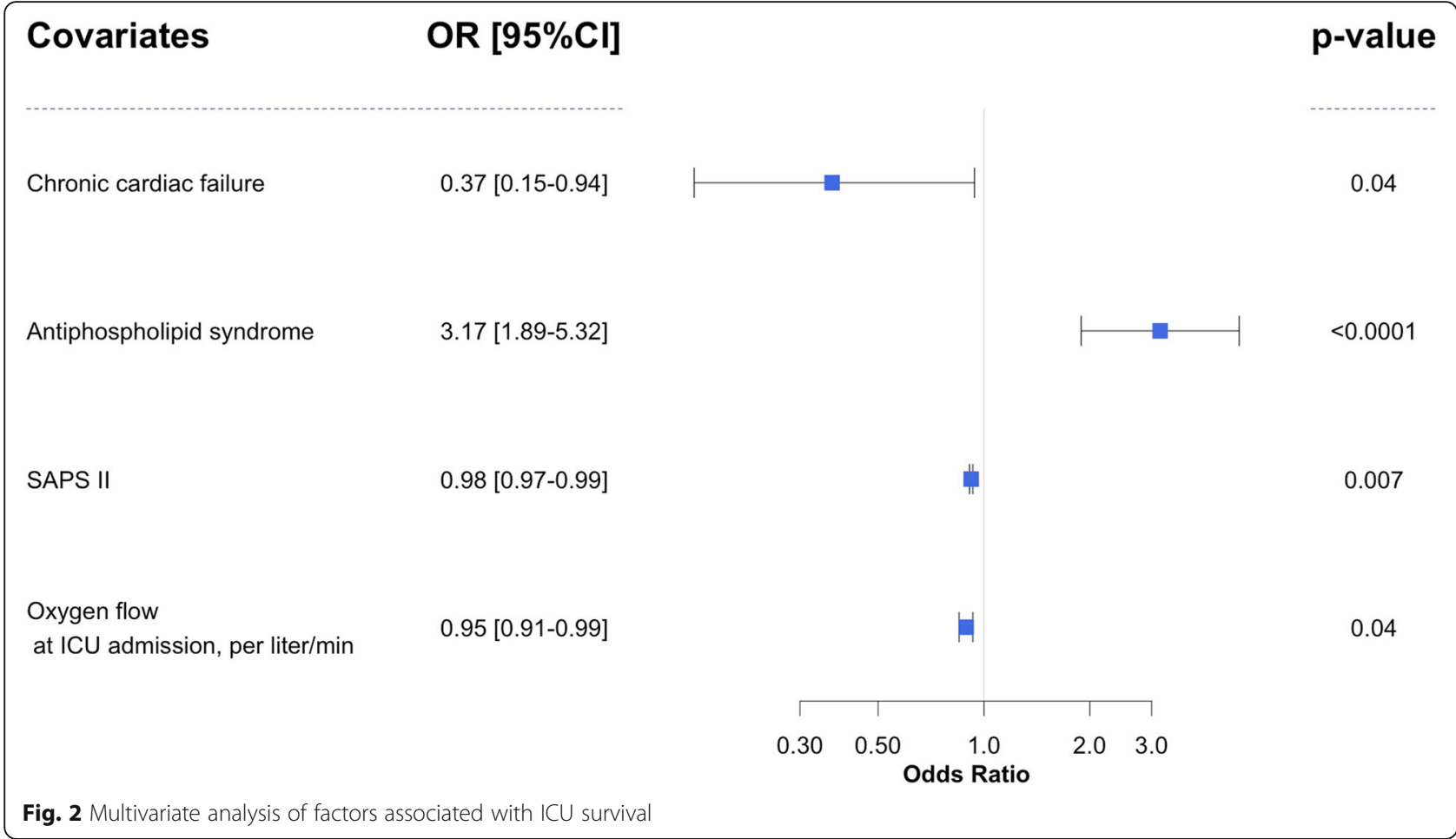

supportive care practices may have changed throughout the study period and influenced the results. Second, for the diagnosis of DAH, we used a database encoded by physicians at patient ICU discharge and we cannot exclude that some patients with autoimmune diseaserelated DAH had been missed. Third, we mixed patients with different autoimmune diseases which mean different prognosis and different management. However, most patients were admitted before autoimmune disease diagnosis. This study might provide some practical data to initially manage these patients with a DAH and a suspected autoimmune disease.

\section{Conclusion}

In conclusion, DAH related to autoimmune disease is a rare but potentially dreadful complication that requires mechanical ventilation in half of the cases admitted to ICU. Age, small-vessel vasculitis, and the time from dyspnea onset to ICU admission were associated with a longer mechanical ventilation duration. The best initial regimen remains to be determined.

\section{Supplementary information}

Supplementary information accompanies this paper at https://doi.org/10 1186/s13054-020-02936-0.

Additional file 1: Table S1. supplementary data on patients with DAH and according to the presence of a vasculitis or a connective tissue disorder. Table S2. univariate analysis according to plasma exchange therapy. Table S3. Univariate analysis of factors associated with mechanical ventilation weaning. Table $\mathbf{S 4}$. Univariate analysis of respiratory and vital status outcomes according to diffuse alveolar hemorrhage treatment.

\section{Abbreviations}

ARDS: Acute respiratory distress syndrome; ANCA: Anti-neutrophil cytoplasmic antibodies; APS: Antiphospholipid syndrome; DAH: Diffuse alveolar hemorrhage; ICU: Intensive care unit; LDH: Lactate dehydrogenase; PLEX: Plasma exchange therapy; SAPS II: Simplified Acute Physiology Score; SLE: Systemic lupus erythematosus

\section{Acknowledgements \\ None.}

\section{Authors' contributions}

AM, MRR, and DS have made substantial contributions to the conception, the design of the work, and the acquisition, analysis, and interpretation of data and have drafted the work or substantively revised it. They have approved the submitted version (and any substantially modified version that involves the author's contribution to the study). They have agreed both to be personally accountable for the author's own contributions and to ensure that questions related to the accuracy or integrity of any part of the work, even the ones in which the author was not personally involved, are appropriately investigated and resolved, and the resolution documented in the literature.

$A P, V A, A D, J M, G G, E M, N B, N d P, M V, M N, N B, E d M, P C$, and JC have made substantial contributions to the acquisition and analysis of data. They have approved the submitted version (and any substantially modified version that involves the author's contribution to the study). They have agreed both to be personally accountable for the author's own contributions and to ensure that questions related to the accuracy or integrity of any part of the work, even the ones in which the author was not personally involved, are appropriately investigated and resolved, and the resolution documented in the literature. 


\section{Funding}

None.

\section{Availability of data and materials}

Not available.

\section{Ethics approval and consent to participate}

According to the Frenck law, a waiver of consent was obtained. The study was approved by local Ethic Committee.

\section{Consent for publication}

Not applicable.

\section{Competing interests}

None.

\section{Author details}

'Département Hospitalo-Universitaire

Inflammation-Immunopathologie-Biotherapie (DHU i2B), UPMC Université Paris 06, UMR 7211, Sorbonne Universités, 75005 Paris, France. ${ }^{2}$ INSERM, UMR_S 959, 75013 Paris, France. ${ }^{3}$ CNRS, FRE3632, 75005 Paris, France. ${ }^{4}$ Département de Médecine Interne et Immunologie Clinique, National Center for Autoimmune and Systemic Diseases and National Center for Autoinflammatory Diseases and Amyloidosis, APHP, Groupe Hospitalier Pitié-Salpêtrière, 75013 Paris, France. ${ }^{5}$ Service de Pneumologie, Hôpital Tenon, APHP, Paris, France. ${ }^{6}$ Département de Biostatistiques, Hôpital Saint-Louis, APHP, Paris, France. ${ }^{7}$ Service de Réanimation Médicale et Pneumologie, Hôpital Pitié-Salpêtrière, APHP, Paris, France. ${ }^{8}$ Service de Réanimation Médicale, Hôpital Cochin, APHP, Paris, France. ${ }^{9}$ Service de Réanimation Médicale, Hôpital Saint-Louis, APHP, Paris, France. ${ }^{10}$ Service de Réanimation Médicale, Hôpital Pitié-Salpêtrière, APHP, Paris, France. ${ }^{11}$ Service de Réanimation Médicale, Hôpital Henri Mondor, APHP, Créteil, France. ${ }^{12}$ Service de Médecine Interne, CHU de Caen, Caen, France. ${ }^{13}$ Service de Réanimation Médicale, Hôpital Bichat, APHP, Paris, France. ${ }^{14}$ Service de Réanimation Médicale, Hôpital Saint-Antoine, Paris, France. ${ }^{15}$ Service de Réanimation Medico-chirurgicale, Hôpital Delafontaine, Saint-Denis, France.

Received: 19 November 2019 Accepted: 30 April 2020

Published online: 18 May 2020

\section{References}

1. Collard HR, Schwarz MI. Diffuse alveolar hemorrhage. Clin Chest Med. 2004; 25:583-92 vii.

2. Lara AR, Schwarz MI. Diffuse alveolar hemorrhage. Chest. 2010;137:1164-71.

3. de Prost N, Parrot A, Cuquemelle E, Picard C, Antoine M, Fleury-Feith J, et al. Diffuse alveolar hemorrhage in immunocompetent patients: etiologies and prognosis revisited. Respir Med. 2012:106:1021-32.

4. Demiselle J, Auchabie J, Beloncle F, Gatault P, Grangé S, Du Cheyron D, et al. Patients with ANCA-associated vasculitis admitted to the intensive care unit with acute vasculitis manifestations: a retrospective and comparative multicentric study. Ann Intensive Care. 2017;7:39.

5. Dumas G, Géri G, Montlahuc C, Chemam S, Dangers L, Pichereau C, et al. Outcomes in critically ill patients with systemic rheumatic disease: a multicenter study. Chest. 2015;148:927-35.

6. Yates M, Watts RA, Bajema IM, Cid MC, Crestani B, Hauser T, et al. EULAR/ ERA-EDTA recommendations for the management of ANCA-associated vasculitis. Ann Rheum Dis. 2016;75:1583-94.

7. Bertsias GK, Tektonidou M, Amoura Z, Aringer M, Bajema I, Berden JHM, et al. Joint European League Against Rheumatism and European Renal Association-European Dialysis and Transplant Association (EULAR/ERA-EDTA) recommendations for the management of adult and paediatric lupus nephritis. Ann Rheum Dis. 2012;71:1771-82.

8. Tse JR, Schwab KE, McMahon M, Simon W. Rituximab: an emerging treatment for recurrent diffuse alveolar hemorrhage in systemic lupus erythematosus. Lupus. 2015;24:756-9.

9. Cartin-Ceba R, Peikert T, Ashrani A, Keogh K, Wylam ME, Ytterberg S, et al. Primary antiphospholipid syndrome-associated diffuse alveolar hemorrhage. Arthritis Care Res (Hoboken). 2014;66:301-10.

10. Cartin-Ceba R, Diaz-Caballero L, Al-Qadi MO, Tryfon S, Fervenza FC, Ytterberg SR, et al. Diffuse alveolar hemorrhage secondary to antineutrophil cytoplasmic antibody-associated vasculitis: predictors of respiratory failure and clinical outcomes. Arthritis Rheumatol (Hoboken, NJ). 2016:68:1467-76.

11. Jayne DRW, Gaskin G, Rasmussen N, Abramowicz D, Ferrario F, Guillevin L, et al. Randomized trial of plasma exchange or high-dosage methylprednisolone as adjunctive therapy for severe renal vasculitis. J Am Soc Nephrol. 2007;18:2180-8

12. Szpirt WM, Heaf JG, Petersen J. Plasma exchange for induction and cyclosporine a for maintenance of remission in Wegener's granulomatosis-a clinical randomized controlled trial. Nephrol Dial Transplant. 2011;26:20613.

13. Walsh M, Merkel PA, Peh C-A, Szpirt WM, Puéchal X, Fujimoto S, et al. Plasma exchange and glucocorticoids in severe ANCA-associated vasculitis. N Engl J Med. 2020;382:622-31.

14. de Groot K, Harper L, Jayne DRW, Flores Suarez LF, Gregorini G, Gross WL, et al. Pulse versus daily oral cyclophosphamide for induction of remission in antineutrophil cytoplasmic antibody-associated vasculitis: a randomized trial. Ann Intern Med. 2009:150:670-80.

15. Jones RB, Tervaert JWC, Hauser T, Luqmani R, Morgan MD, Peh CA, et al. Rituximab versus cyclophosphamide in ANCA-associated renal vasculitis. N Engl J Med. 2010;363:211-20.

16. Stone JH, Merkel PA, Spiera R, Seo P, Langford CA, Hoffman GS, et al. Rituximab versus cyclophosphamide for ANCA-associated vasculitis. N Engl J Med. 2010;363:221-32

17. Petri M, Orbai A-M, Alarcón GS, Gordon C, Merrill JT, Fortin PR, et al. Derivation and validation of systemic lupus international collaborating clinics classification criteria for systemic lupus erythematosus. Arthritis Rheum. 2012;64:2677-86.

18. Jennette JC, Falk RJ, Bacon PA, Basu N, Cid MC, Ferrario F, et al. 2012 revised International Chapel Hill Consensus Conference Nomenclature of Vasculitides. Arthritis Rheum. 2013:65:1-11.

19. Miyakis S, Lockshin MD, Atsumi T, Branch DW, Brey RL, Cervera R, et al. International consensus statement on an update of the classification criteria for definite antiphospholipid syndrome (APS). J Thromb Haemost. 2006;4: 295-306.

20. Charlson ME, Pompei P, Ales KL, Mackenzie CR. A new method of classifying prognostic comorbidity in longitudinal studies: development and validation. J Chronic Dis. 1987:40:373-83.

21. Le Gall JR, Lemeshow S, Saulnier F. A new Simplified Acute Physiology Score (SAPS II) based on a European/North American multicenter study. JAMA. 1993;270:2957-63.

22. Vincent J-L, Rello J, Marshall J, Silva E, Anzueto A, Martin CD, et al. International study of the prevalence and outcomes of infection in intensive care units. JAMA. 2009:302:2323-9.

23. ARDS Definition Task Force, Ranieri VM, Rubenfeld GD, Thompson BT, Ferguson ND, Caldwell $E$, et al. Acute respiratory distress syndrome: the Berlin Definition. JAMA. 2012;307:2526-2533

24. Acute Kidney Injury (AKI) - KDIGO [Internet]. [cited 2017 Sep 4]. Available from: http://kdigo.org/guidelines/acute-kidney-injury/.

25. Kostianovsky A, Hauser T, Pagnoux C, Cohen P, Daugas E, Mouthon L, et al. Alveolar haemorrhage in ANCA-associated vasculitides: 80 patients' features and prognostic factors. Clin Exp Rheumatol. 2012:30:S77-82.

26. Holguin F, Ramadan B, Gal AA, Roman J. Prognostic factors for hospital mortality and ICU admission in patients with ANCA-related pulmonary vasculitis. Am J Med Sci. 2008;336:321-6.

27. Hruskova Z, Casian AL, Konopasek P, Svobodova B, Frausova D, Lanska V, et al. Long-term outcome of severe alveolar haemorrhage in ANCA-associated vasculitis: a retrospective cohort study. Scand J Rheumatol. 2013;42:211-4.

28. Rabe C, Appenrodt B, Hoff C, Ewig S, Klehr HU, Sauerbruch T, et al. Severe respiratory failure due to diffuse alveolar hemorrhage: clinical characteristics and outcome of intensive care. J Crit Care. 2010:25:230-5.

29. Yachoui R, Sehgal R, Amlani B, Goldberg JW. Antiphospholipid antibodiesassociated diffuse alveolar hemorrhage. Semin Arthritis Rheum. 2015:44: 652-7.

30. Lemiale V, Lambert J, Canet E, Mokart D, Pène F, Rabbat A, et al. Identifying cancer subjects with acute respiratory failure at high risk for intubation and mechanical ventilation. Respir Care. 2014;59:1517-23.

31. Adda M, Coquet I, Darmon M, Thiery G, Schlemmer B, Azoulay E. Predictors of noninvasive ventilation failure in patients with hematologic malignancy and acute respiratory failure. Crit Care Med. 2008;36:2766-72.

32. Antonelli M, Conti G, Moro ML, Esquinas A Gonzalez-Diaz G, Confalonieri M, et al. Predictors of failure of noninvasive positive pressure ventilation in 
patients with acute hypoxemic respiratory failure: a multi-center study Intensive Care Med. 2001;27:1718-28.

33. Mirouse A, Vignon P, Piron P, Robert R, Papazian L, Géri G, et al. Severe varicella-zoster virus pneumonia: a multicenter cohort study. Crit Care. 2017; 21:137.

34. Kao K-C, Hu H-C, Fu J-Y, Hsieh M-J, Wu Y-K, Chen Y-C, et al. Renal replacement therapy in prolonged mechanical ventilation patients with renal failure in Taiwan. J Crit Care. 2011;26:600-7.

\section{Publisher's Note}

Springer Nature remains neutral with regard to jurisdictional claims in published maps and institutional affiliations.

Ready to submit your research? Choose BMC and benefit from:

- fast, convenient online submission

- thorough peer review by experienced researchers in your field

- rapid publication on acceptance

- support for research data, including large and complex data types

- gold Open Access which fosters wider collaboration and increased citations

- maximum visibility for your research: over $100 \mathrm{M}$ website views per year

At BMC, research is always in progress.

Learn more biomedcentral.com/submissions 